\title{
Research on the Present Situation and
} Countermeasures of International Production Capacity Cooperation in Hebei Province under the
Background of "the Belt and Road Initiative"

\author{
Liu Haiyun \\ International Business Research Institute of CEEC \\ Hebei University of Economics and Business \\ Shijiazhuang, People’s Republic of China \\ yunhebei@126.com
}

\author{
Zhang Jinzhe \\ International Education School \\ Hebei University of Economics and Business \\ Shijiazhuang, People’s Republic of China \\ 1064279362@qq.com
}

\begin{abstract}
The implementation of "the Belt and Road Initiative" (B\&R) increases new impetus in China's economic development. Infrastructure construction cooperation of railways, highways, aviation and ports has become a new breakthrough in economic development. The cooperation ways based on production capacity cooperation will be the key field in the "B\&R". The paper analyzes the current situation of China's international production capacity cooperation under the background of the " $B \& R$ " and puts forward some countermeasures and suggestions to solve the problems in the international capacity cooperation of Hebei Province.
\end{abstract}

Keywords-the Belt and Road Initiative, International Production Capacity Cooperation, International Production Capacity Cooperation in Hebei Province

International production capacity cooperation is not only an important approach to resolve the excess production capacity and carry out structural reform of the supply front, but also a new approach to optimize production factors allocation, further reduce costs and enhance profits. In order to promote "the Belt and Road Initiative” (“B\&R”)production capacity cooperation, China's railway, nuclear power, iron and steel, nonferrous metal and building materials and other high-quality production capacity are constantly "going out", the overseas investment and projects contracting are growing vigorously. With the publishing of Guidance on Promoting International Production Capacity and Equipment Manufacturing Cooperation on May 16, 2015, it led a large number of domestic equipment, technology, services, standards and brands to further "go out". In November, 2016, the Central and Eastern European Leaders Summit in Latvia provided a new opportunity to transport and logistics trade exchanges.

\section{The Present Situation And Problems of INTERNATIONAL PRODUCTION CAPACITY COOPERATION IN Hebei PRovince}

A. The amount of overseas investment increases significantly, but there is still a gap with the developed areas.

In recent years Hebei Province has been strengthening international production capacity cooperation. In the end of 2015 there were totally over 700 overseas investment enterprises approved and registered in Hebei Province with 11 billion USD investment of which China's investment reached 8.8 billion USD. According to the statistics, Hebei overseas investment was involved in more than 20 industries such as iron and steel, cement, glass, equipment manufacturing, new energy and textile clothing with 8.95 million tons of steel, 4.38 tons of cement as well as 0.85 million weight boxes. In 2015 there were 131 additional registered overseas investment enterprises with 3.06 billion USD capitals, an increase of $80.8 \%$, of which China invested 2.35 billion USD, an increase of $51.5 \%$.[1] Recently a series of progressing production capacity cooperation projects include the operation of onemillion-ton cement in Mamba of South Africa by Jidong Development Group and six-million-ton mill coil in Thailand by Delong Steel, as well as the construction of an annual 80 thousands of SUV production in Russia invested by Great Wall Group, glass production line of 0.85 weight boxes in Tanzania invested by Zhuangda Glass Corporation, etc..[21]

Although there is rapid increasing of overseas investment of Hebei Province, there is still a gap with other developed regions in China. According to the information provided by Dongguan Municipal Bureau of Commerce, as of October 2015, there were 316 overseas projects operated by 420 enterprises in Dongguan, especially in Southeast Asia, Africa and South America. During the first eight months, Dongguan exporting values 13.03 billion USD in the "B\&R" countries, an increase of $42 \%$, that becomes the third largest exporting market. [3]The investment amount of Dongguan exceeds the total amount of Hebei Province. 


\section{B. The investment mode is relatively simple.}

Currently the overseas investment mode of Hebei Province is still dominated by FDI and establishing factories, the investment mode is relatively simple, overseas financing ability is insufficient with high risk management. Unfamiliar with foreign commercial customs, legal environment and lack of international project experience happen in project landing and penalty. At present similar events has happened in Burma, Vietnam, Sri Lanka and Thailand and some important investment projects are compelled to cease. Because of unfamiliar with foreign economic situation, the technological standard of production capacity cooperation is not identical. For example some Middle East countries lacking of advanced technology appreciate the industrial technology and standard of Europe and USA, there is tremendous pressure for Chinese enterprises in the overseas investment.

\section{International production capacity is still dominated by traditional industries.}

Currently the international production capacity cooperation of Hebei Province mainly focuses on traditional industries such as steel, cement, glass and textile. The constructed and constructing projects of 8.95 million tons of steel, 4.38 million tons of cement, 0.85 million weight boxes of glass belong to the traditional industries. There are some relatively large overseas investment projects, for example Bazhou Xinya Metal Corporation acquired 30\% stock right of Java Pacific Co, Ltd. in Indonesia and extended the projects of galvanized steel strip (GI STRIP) and furniture pipe so that it attempted to 350 thousand tons of GI STRIP production line in the first half year of 2015. In 2016 it launched the construction of an annual 200 thousand tons of furniture pipe. Hebei Bishi Group planned to invest 4.5 billion USD to set up a steel rolling factory and a thermal power station covering 1000 hectares in South Sulawesi with 4X135 megawatt generating capacity and annual 4-5 million tons steel rolling. In 2014 Hebei Xindadong Textile Co, Ltd. Invested 49 million USD to establish a textile factory in Da Nang of Vietnam. Recently 100 thousand of top-grade yarn has been operated.[4] In 2015 the main equipment of Phase I Project of Iraq MASS steel Han-Steel of Hebei Iron \& Steel Group(HBIS) was installed and under commissioning. The project is the first time that Han-Steel is engaged in equipment maintenance and production which symbolizes a significant step to explore overseas construction technological market of Han-Steel. On April 18, 2016 HBIS signed an acquisition agreement with Smederevo Iron \& Steel, the only national steel factory in Serbia, and accepted the factory with 5050 workers.[5] The acquisition of Smederevo Iron \& Steel is part of HBIS “goingout” strategy, which is an important attempt under the background of excess production capacity and meager profit. It not only realizes local production in Europe, avoids European anti-dumping and anti-subsidy to Chinese steel, but also promotes the local employment and economic development.

D. The development of overseas cooperation districts in Hebei Province is unbalanced.

The districts of overseas cooperation are concentrated in cities of Shijiazhuang and Tangshan. For example, Tangshan vigorously implements the "going-out" strategy, as of the end of 2015; there were 101 approvals overseas investment projects with 2.008 billion USD totally among which China invested 1.255 billion US. There were 15 foreign contracted project enterprises, three overseas labor service enterprises, 75 foreign contracted projects and 12 foreign aid projects, with a turnover of 3.32 billion USD. [6]The "going-out" business has been distributed in 63 countries and regions. The proportion of investment in developed countries and emerging market countries gradually increased, $70 \%$ of the investment areas were located in the prospective market in United States, Germany, Italy, Russia, South Africa, etc.. [7]According to Shijiazhuang City Bureau of Commerce statistics, it shows that as of the end of 2014, there were 33 additional registered overseas investment enterprises, an increase of $43.48 \%$, total investment of 450 million USD, an increase of 89.96\%; Chinese investment of 390 million USD, an increase of $84.42 \%$. It stood first on the list of the number of investment enterprises and aggregate investment.[8] As of 2015, there had been 161 municipal record enterprises of overseas investment with 940 million USD in more than 30 countries and regions. Except Shijiazhuang and Tangshan, the international production capacity of other districts of Hebei Province is insufficient with a small amount of overseas investment capital, which reflects the characteristics of regional imbalance.

\section{Suggestions On PROMOting INTERnAtionaL Production Cooperation in Hebei Province}

\section{A. To expand publicity and exchanges, establish a new concept of international production cooperation}

Public opinion is leading in the economic development. Firstly, it should strengthen the publicity and guidance of the "B\&R" strategy. The "B\&R" Construction is not only a major measure for China to expand and deepen its opening, but also a sublimation of China's open development concept in concrete practice. Through opening mind, strengthening selfconfidence and promote opening ability, it will pursue common development, prosperity and cooperation. Secondly, a new concept of international production capacity cooperation should be established. With international production capacity cooperation, China's high-quality production capacity and advantageous equipment should combine with the key technologies and advanced equipment in developed countries.

Through international production capacity, with the vast number of emerging economies and developing countries, urbanization and industrialization needs docking. It brings a new impetus to global economic recovery, but also opens up new space for China's economic stability, moreover creates new opportunities for advancing win-win cooperation. Meanwhile, the international production capacity cooperation is an important way to solve excess capacity and implement supply-side structural reform, but also a new approach to optimize the allocation of production factors, lower the cost and promote the profit. Thirdly, conferences of various levels should be held to provide decision-making references for the "B\&R". 


\section{B. Funded by the government, the overseas venture capital fund provides financial support for international production cooperation in Hebei Province.}

The sources of overseas venture capital fund can be varied not only from policy banks, but also from the social security fund. With the operation and development of foreign social security fund for years, it occupies the capital market. In foreign countries, the pension insurance fund occupies $25 \%$ $45 \%$ of the whole capital market, even more than $30 \%$ in the stock exchange in New York and London.[9] In the operation of foreign pension insurance fund, it contains double effects that it preserves and increases the value and plays an active role in stabilizing the domestic capital market. With the continuous improvement of our old-age insurance system and the continuous improvement of capital market, the entry of social security fund into the capital market has been recognized and valued by the government departments. Compared with the domestic capital market, the foreign markets develop earlier and more mature. There is much experience to learn from the foreign market. Through the operation of foreign venture capital, it will provide financial support to the international production capacity cooperation in Hebei Province.

\section{To actively explore new ways of foreign investment, increase the construction of overseas industrial parks}

Overseas economic and trade cooperation zones have become an important gathering platform for international production capacity cooperation. The data shows that by the end of 2015, Chinese enterprises invested 75 economic and trade industrial parks in 34 countries with the cumulative investment of nearly 20 billion USD to achieve the output value of 40 billion USD, tax of 1.41 billion USD and 154 thousand of jobs. [10]Through the establishment of production capacity cooperation platform mechanism, the overseas industrial parks provide information sharing and investment promotion, and play an important role in promoting China's advanced manufacturing industry, new service industry, processing industries and other overseas investment. Meanwhile the industrial parks utilize their integrated service development capabilities to provide high standards of infrastructure, business, education, medical and other facilities.

\section{To support the construction of intermediary institutions, serve state-owned and private enterprises, combine traditional and emerging industries for overseas investment}

In the perspective of international experience, accounting firms, law firms, investment banks and securities companies, credit, rating agencies play an important role in cross-national production capacity cooperation. Hebei Province should strengthen supporting, cultivate relevant agencies and promote the above organizations to "go out". In addition, Shangdong Province, Hubei Province and Dongguan City utilize the relevant agencies to offer overseas investment experience, encourage the state-owned and private enterprises, the traditional and emerging industries to make overseas investment in group in order to promote the abilities of marketing competitiveness and resisting risks.

\section{E. To support the construction of intermediary institutions, serve state-owned and private enterprises, combine traditional and emerging industries for overseas investment}

In the perspective of international experience, accounting firms, law firms, investment banks and securities companies, credit, rating agencies play an important role in cross-national production capacity cooperation. Hebei Province should strengthen supporting, cultivate relevant agencies and promote the above organizations to "go out". In addition, Shangdong Province, Hubei Province and Dongguan City utilize the relevant agencies to offer overseas investment experience, encourage the state-owned and private enterprises, the traditional and emerging industries to make overseas investment in group in order to promote the abilities of marketing competitiveness and resisting risks.

\section{F. To strengthen the construction of a new type of think tank in Hebei Province and provide investment advisory services for overseas investment}

There are huge differences in history, culture, politics and economy of the "B\&R" countries, which brings risks to overseas investment. Scientific assessment of the relevant national investment risk and careful choice of the cooperation countries should be preconditions of the " $B \& \mathrm{R}$ " production capacity cooperation. Currently China is strengthening think tank construction that plays an important role in implementing the "B\&R" strategy. Hebei Province should increase investment and establish new think tanks meeting Hebei economic demands. With the think tanks, the analytic research on politics, economy, culture, industry and environment of the "B\&R" countries and serve Hebei enterprises "going-out" to implement production capacity cooperation.

\section{CONCLUSION}

As the amount of overseas investment increases significantly, the investment modes are relatively simple and dominated by traditional industries. It should be concerned on expanding publicity and exchanges, establishing a new concept of international production cooperation. Funded by the government, the overseas venture capital fund provides financial support for international production cooperation in Hebei Province. The government needs to strengthen the construction of a new type of think tank and provide investment advisory services for overseas investment.

\section{REFERENCES}

[1] Jiang Anyin, “Mutual Reference of China’s Development Experience in the Construction of the Belt and Road Initiative-Taking Infrastructure Construction as an Example,” China Circulation Economy, vol. 12, 2015.

[2] Guo Chaoxian, et al. "Development and Suggestions on the Belt and Road Initiative Production Capacity Cooperation,” China National Conditions and Strength, vol. 4, 2016.

[3] Li Chunlin, et al. "One Belt and One Road Construction and Paradigm Shift of International Development Cooperation," Economy and Management, vol. 6, 2015.

[4] Jin Ling, “The Belt and Road Initiative-China's Marshall Plan?” International Studies, vol. 1, 2015. 
[5] Li Dan, et al. "The Belt and Road Initiative and Reconstruction of World Economic Structure,” Economist, vol. 8, 2015.

[6] Song Guoyou, “The Belt and Road Initiative and China's Economic Development,” International Survey, vol.7, 2015.

[7] http://midchina.xinhuanet.com/2017-01/11/c_1120290586.htm, Foreign Investment of Hubei Province Enterprises in Group.

[8] https://sanwen8.cn/p/1e0gbJS.html, China’s Foreign Investment of Iron and Steel in 2015.

[9] http://news.ifeng.com/a/20160328/48234944_0.shtml, 700 Hebei Enterprises Invest 8.8 Billion USD.

[10] http://finance.qq.com/a/20160322/059522.htm, Report on National Overseas Investment in 2016. 